\title{
Fear, guilt, and debt: an exploration of women's experience and perception of cesarean birth in Burkina Faso,West Africa
}

This article was published in the following Dove Press journal:

International Journal of Women's Health

5 May 2014

Number of times this article has been viewed

\section{Fabienne Richard' \\ Sylvie Zongo ${ }^{2}$ \\ Fatoumata Ouattara ${ }^{3}$}

'Maternal and Reproductive Health Unit, Department of Public Health, Institute of Tropical Medicine, Antwerp, Belgium; ${ }^{2}$ Institut de Recherche pour le Développement, Burkina Faso, West Africa; ${ }^{3}$ Institut de Recherche pour le Développement UMR 912, "Sciences Economiques et Sociales de la Santé et Traitement de I'Information Médicale - SESSTIM", Marseille, France
Correspondence: Fabienne Richard Maternal and Reproductive Health Unit, Department of Public Health, Institute of Tropical Medicine, Nationalestraat I55, 2000 Antwerp, Belgium

Tel +3232476664

Fax +3232476258

Email frichard@itg.be
Background: This paper explores women's experience and perception of cesarean birth in Burkina Faso and its social and economic implications within the household.

Methods: Five focus groups comprising mothers or pregnant women were conducted among residents of Bogodogo Health District in Ouagadougou to assess the perceptions of cesarean section (CS) by women in the community. In addition, 35 individual semistructured interviews were held at the homes of women who had just undergone CS in the referral hospital, and were conducted by an anthropologist and a midwife.

Results: Home visits to women with CS identified common fears about the procedure, such as "once you have had a CS, you will always have to deliver by CS". The central and recurring theme in the interviews was communication between patients and care providers, ie, women were often not informed of the imminence of CS in the delivery room. Information given by health care professionals was often either not explicit enough or not understood. The women received insufficient information about postoperative personal hygiene, diet, resumption of sexual activity, and contraception. Overall, analysis of the experiences of women who had undergone CS highlighted feelings of guilt in the aftermath of CS. Other concerns included the feeling of not being a "good mother" who can give birth normally, alongside concerns about needing a CS in future pregnancies, the high costs that this might incur for their households, general fatigue, and possible medical complications after surgery.

Conclusion: Poor quality of care and the economic burden of CS place women in a multifaceted situation of vulnerability within the family. CS has a medical, emotional, social, and economic impact on poor African women that cannot be ignored. Managers of maternal health programs need to understand women's perceptions of CS so as to overcome existing barriers to this life-saving procedure.

Keywords: cesarean section, quality of care, access to care, anthropology

\section{Introduction}

Cesarean section (CS) is a major obstetric procedure. It can save lives (both mother and child) in the event of serious complications. ${ }^{1}$ The debate about the ideal CS rate is ongoing and shows no sign of abating. ${ }^{1-9}$ Whereas in the past the discussion revolved largely around medical issues and whether or not CS could be justified, the question of the woman's right to choose her own mode of delivery without a medical indication has now taken center stage. ${ }^{10,11}$ This right to CS is an extension of the "a child if I want, when I want, and with whom I want" view which some see as the rights of women with regard to their own bodies. However, others believe that women who request a CS are victims of overmedicalization or the influence of doctors who can no longer bear the screams and sweat of a delivery room and prefer a more rapid and lucrative CS. ${ }^{10,12-14}$ 
The woman's right to choose her delivery method has been a matter of debate, mostly in countries with a high CS rate. In other countries, such as those in sub-Saharan Africa, where the CS rate is less than $2 \%$, improving accessibility is a priority. How can low CS rates be explained in these settings? Financial and geographical access seems to be a major barrier. However, some authors ${ }^{15-18}$ also point to the importance of social acceptability of CS by women and their families in sub-Saharan Africa. They see CS not only as an inability or failure of the woman to deliver vaginally ${ }^{15}$ but also as a threat to the family's financial stability. ${ }^{19-21}$ Those involved in maternal health programs need to understand women's perceptions of CS so as to overcome existing barriers (eg, through reduction of the direct costs of CS or improved transport to a referral hospital) and see their efforts come to fruition.

The objective of this paper was to explore women's experience with and perception of CS in Burkina Faso and the social and economic implications of CS within the household.

\section{Materials and methods}

We conducted a qualitative study using focus groups and individual semistructured interviews (Supplementary material). This study was part of a larger multidisciplinary action research project (AQUASOU) ${ }^{22}$ aiming to improve the quality of and access to emergency obstetric care in the health district of Bogodogo, Burkina Faso. It was based on the coordination and synergy of three complementary approaches, ie, public health, social anthropology, and political and social mobilization.

\section{Study setting}

Bogodogo district is one of five districts in the Center Health Region and covers a population of approximately half a million people, of whom $67 \%$ are from rural areas. The district comprises 41 first-level facilities (public and private) which refer complicated cases to the district hospital. The district hospital in Bogodogo has 57 beds for pediatrics, surgery, medicine, maternity ( 24 beds), an outpatient clinic, a laboratory, and a medical imaging unit (radiography and ultrasound). The operating theater opened on August 1, 2003, but emergency obstetric surgery has only been possible for 24 hours on 7 days a week since October 1, 2004. Admissions to the maternity ward (operational since November 2001) have increased rapidly, doubling in number between 2002 and 2005 (from 2,053 to 4,182). In 2004, the hospital performed 193 CS versus 506 in 2005 and 735 in 2009 . The interviews and focus groups were conducted 10 years ago when the hospital was increasing its CS offer but out-of-pocket expenditure was still high. No exemption system was in place in 2003 and 2004 to decrease the financial burden to the household. In 2005, the district initiated a cost-sharing system to decrease the direct household costs for a CS from 74.000 CFA (US\$136) to 25.000 CFA (US\$46). In late 2006, the government launched a national subsidy for delivery and emergency obstetric care so as to cover $80 \%$ of the direct costs, and the direct costs of CS were officially reduced to 11.000 CFA (US\$22). These women's views on CS can be considered as a baseline prior to introduction of the national subsidy. Given that some research teams are now evaluating the impact of exemption policies on the perception of CS in West Africa, this paper will allow comparison "before and after the introduction of an exemption policy for obstetric services".

\section{Individual semistructured interviews}

A team of one anthropologist and one health provider (midwife or theater nurse) conducted home visits for patients who underwent a cesarean birth at Bogodogo District Hospital in Ouagadougou. Interviews started in September 2003 and continued until September 2004. A health care provider was added to the research team following a situational analysis conducted during the first year of the AQUASOU project that demonstrated a lack of health provider knowledge of patients' social conditions. ${ }^{23}$

The objective of the home visits was two-fold: the first was to collect the women's experience of cesarean birth and second to "open the eyes" of health care providers by observing the women's living conditions and listening to their testimonies and individual perceptions of care. The expected outcome of the second objective was an improvement in relationships between health care providers and patients. This paper mainly focuses on the first objective.

The majority of health care providers agreed to participate in the home visits. Ten of 15 midwives joined the team. Only the maternity ward staff took part initially, but operating theater personnel subsequently came on board. Thirty-five of 112 women who underwent CS in the operating theater between September 2003 and September 2004 were visited in their homes. One of the anthropologists proposed a home visit to the women before they left the facility, and most agreed after consultation with their husbands. The exact address of the household and (if applicable) a mobile phone number were then recorded by the researcher to ensure location of the home.

Interviews were conducted in Moore (the national language) and written notes were taken by the interviewer. After each visit, a report was drafted in French by the 
interviewer and he/she was expected to provide feedback to his/her colleagues during a subsequent team meeting.

\section{Focus groups with women}

In February 2004, five focus groups were conducted with women who attended various maternity wards in the Health District of Bogodogo (four urban facilities and one rural facility). These focus groups collected data to assess the perceptions of CS by women in the community. Home interviews were embedded in the action research and served as an exploratory phase to prepare for user-provider meetings in the second part of the project.

Each group consisted of about 15 women, which allowed us to look into the subject in greater depth. The composition of the groups was determined during antenatal consultations in the four urban facilities and one rural facility. The activity was proposed to the women, and if they accepted, details, days, and hours of the discussion were given. The meetings were held outside the hospital in a public place.

The objective of the focus group was two-fold. The first objective was to collect data on women's perception of pregnancy, childbirth, and associated problems, including the different views on social support received during pregnancy, ie, who are the people involved in the financial expense of pregnancy and childbirth. The women were asked whether they were satisfied with the care they received and what they would like to see changed regarding access to and organization of the facilities they used. The existence and running of the district hospital's operating theater was also discussed. The second objective was to secure input for the next step, which was organization of user-provider meetings to improve the quality of care. These focus groups allowed the project's promoters to identify the main "touchy" or problematic issues from the women's perspective to be discussed with the providers, eg, informal payment and lack of communication.

Individual home visit interviews and discussions in the user focus groups were conducted in Moore (the national language), audio-recorded, and transcribed into the French language using Microsoft Word.

A content analysis was undertaken manually according to the analysis methodology of qualitative data. ${ }^{24,25}$ No software was used. The authors first read all the interviews to identify the different themes, and each interview was then analyzed according to the themes identified during the first round of reading. The results were triangulated by the two social anthropologists (FO and SZ).

Permission to perform the AQUASOU action research and its different nested studies was obtained from the Ministry of Health of Burkina Faso (MS/SG/DGSP/DSF/27.02.2002) and the Regional Directorate of the Health Center Region. Ethical regulations regarding participant consent and treatment of the data were followed according to the tenets of the Declaration of Helsinki.

\section{Results}

Women with a CS who were later interviewed were representative of the patients hospitalized for CS in the district hospital (Bogodogo district [73\%] and other districts [27\%]), and all originated from urban or semiurban areas. Their average age was 27 (range, 22-33) years, all were married, and had an average of two children at the time of interview. Regarding employment, $38 \%$ were employed in the formal sector (work with an employment contract). Women in the focus group originated from urban $(80 \%)$ or rural $(20 \%)$ areas, and were aged 18-40 years. Most had primary schooling, and were housewives working in the informal sector (street sellers).

\section{Fear of cesarean birth: its unpredictability and consequences}

Almost all women interviewed mentioned the unpredictability of health problems during pregnancy, and felt that no two pregnancies are alike. Some pregnancies were considered to be easier than others:

Pregnancies are all different. You can be pregnant and it hurts, it hurts all the way until the delivery. [Member of the patient focus group linked to an urban maternity ward]

Childbirths, like pregnancies, are all different, with some being quick and easy, while others are difficult, with women suffering a prolonged labor. Fear of childbirth seems to be related to the birth outcome. It is a critical time in a woman's life and for her health. The statement that "childbirth is war" is found in popular representations of childbirth in Nigeria, ${ }^{26}$ but might just as well be a claim of women in Burkina Faso. The method of delivery is also a source of anxiety:

You fear that you are between life and death; some people die in childbirth, or you can give birth and not be healthy. In addition, you get frightened if you believe you may have to undergo an operation. [Member of a patient focus group linked to an urban maternity ward]

A 31-year-old woman, who had studied accountancy and underwent CS described her fears when she learnt she had to have the operation:

I had pain in my lower abdomen, and I was in the maternity ward. The midwife asked me to do an ultrasound so she 
could know the presentation of the baby [...]. When I went to the ultrasound, the guy told me what it was going to be (an operation). He told me that the position of the baby was not really good. And when that happens, it often ends with an intervention. I asked him whether the child could be turned. He told me no, because it was too low, the baby was stuck and had no room to turn. That day, I cried. When I heard those people talk about a CS, I was so scared. [...] People tell so many things, there is a mystery around it. [A woman interviewed at home]

The women's stories generally referred to fears of medical procedures, including CS, as reflected in the statement: "Once a CS, always a CS!", highlighting the fear of repetition. Another aspect often mentioned by the women was a lack of information during their antenatal consultations about the possibility of a cesarean birth. The unpredictability of delivering by CS was a recurrent topic during the interviews.

The interviewees regularly referred to their fear of poor and slow healing of the scar after a CS and the resulting physical side effects, eg, back pain and fatigue. There was intense fear associated with the risk of dying during childbirth, which is probably higher in women who know women who have died during childbirth.

[...] it is our neighbor, she went to give birth. It was serious, she arrived there in the morning, and at $10 \mathrm{pm}$ she had still not given birth. They told her to push, she did not want to push, she did not push, she tightened her buttocks, until she was referred to the hospital. They brought her inside, they came out to hand over the baby, they returned inside. When they returned we saw that they were taking her body to the morgue. Seeing that frightened everyone. [Member of a patient focus group linked to an urban maternity ward]

For others, fear of CS was related to hearing other people's horror stories and tales of serious consequences, such as paralysis of the lower limbs.

\section{Social and economic consequences of cesarean birth}

Fear of childbirth, and more specifically of CS, is inseparable from the medical, social, and financial implications facing women:

If you're going to give birth, you're scared because you do not know how it will happen. You can get a prescription but the money turns out to be a problem [...] [Member of a patient focus group linked to an urban maternity ward]
Men are expected to meet the obstetric care expenses. ${ }^{27,28}$ Very few women know the cost of their CS. This fact does not imply negligence on the part of the women, but reflects the distribution of tasks within marriage. Few men tell their wives what they had to pay. According to the women, men may think it indiscrete if a woman asks this type of question.

[...] When you give birth, except your husband, no one else will come and pay the expenses. Even if your husband has no money, he will borrow and has to reimburse later. [...] If you have given birth, the man must do anything to get the money and come and pay. [Member of a patient focus group linked to an urban maternity ward]

Families are rarely prepared to cover the additional costs of childbirth. In fact, the urgency solves the problem ("when things get hot, we find it [...]"). However, there seems to be a gap between the social norm and reality.

In urban areas and in the context of economic crisis, negotiations and arrangements between men and women about the costs of pregnancy and childbirth are not uncommon. Among men, there are those who are able to pay the costs of delivery, those who do not want to pay, and a large group who do not have the means to pay. In the latter case, women may pay themselves. The strategy adopted by the woman is to ensure that the members of her entourage (family members and caregivers) do not find out that she is the one who pays. For the woman, it is an act of saving her husband's reputation and showing that he is capable of meeting the costs of pregnancy and childbirth.

For example, as I know that my husband did not have the means, I gave him money on the day I was coming out of hospital, 'take it, go and pay and we'll get out', it was my husband who paid, [women laugh]. But in reality, it was me paying. It's just between ourselves, nobody knew. [Member of patient focus group linked to an urban maternity ward]

A teacher explained, for example, that she had covered the costs of her three pregnancies since her husband lost his job. Even for the health care providers, the rule is that the man pays the costs of delivery. Exchanges between caregivers and the patient's companions are limited to giving prescriptions and claiming consultation fees.

In poorer settings, it is difficult to prepare financially for childbirth. Other than the profits from a small business, women try to save on the money their husbands give them to buy condiments, but do not tell them about these savings. Some women say that pregnancy increases tensions in the marriage. According to the women, men do not 
feel concerned by the problems faced by their wives during pregnancy. Discussions can become complicated. In addition to the woman's psychological anxiety, pregnancy and childbirth seem to add tensions to her relationship with her partner. The man seems to reach a critical point where his reputation in his close circle is at stake, and rests on his capacity to pay hospitalization bills. Motherhood thus becomes a threat to the social status of both the man and the woman.

Fear or refusal of certain medical procedures (including emergency referral to the hospital) is mainly due to concern about incurring higher costs in a complex medical environment where patients receive little information. ${ }^{29}$

\section{Lack of communication about CS by health care providers}

Communication or the lack of it was a recurrent theme in the various interviews conducted at home and in the focus groups. In addition to this lack of information, the interactions between health care providers and users seem underpinned by a breakdown of communication.

For example, some women said that they were not informed of the decision to perform a CS in the delivery room. Raisa is a 25-year-old mother. We visited her after she underwent a CS. She said she had attended six antenatal consultations. She was carrying twins who died after the procedure. She did not have the chance to see them and said she had not been informed about the CS:

They put me on a stretcher in the maternity ward to bring me to the operating theater. It was then that I knew that they were going to operate. [Young woman, mother of one child, during interview conducted at home in February 2004]

In many cases, information given by staff is not understood because it is too vague. One of the objectives of having a health care provider on the team of interviewers during the home visits was to improve this communication and help providers to realize that the information given can have a significant impact in the weeks following a cesarean birth.

For example, Rosalie, a 25-year-old woman who was told that she needed an operation because her baby was too large (her medical file stated "generally contracted pelvis"), said that she would ensure that her next child was smaller. She told the interviewers when she was interviewed at home that she would avoid eating food that boosted her baby's growth. Another woman who was told to avoid soaking the wound in water after a CS interpreted this as meaning that she could not wash herself. During the home visit, several days after her return home, the caregiver noticed the smell and physical appearance of this young mother. The home visit provided the opportunity to show the mother how to wash herself. In order to facilitate free discussion, the health care provider was not the one involved in management of the delivery.

Initially, many patients were surprised or scared when midwives and anthropologists visited them in their homes. A caregiver visiting a patient at home to listen to her story was unheard of in the local history of Burkina Faso. The team sometimes encountered reluctance from the women or their families. One woman, whose husband the team wanted to interview, later confided the reason for her reluctance: "I was scared and wondered what my husband had done for the team wanting to see him!" However, after some initial surprise, when families realized that they had done nothing wrong and that the health care provider was open and attentive, there was a high demand from mothers for information on personal hygiene, eating habits, and resumption of sexual activity after CS.

\section{Discussion}

\section{Aversion to cesarean birth}

Several papers from Nigeria, a country that, like Burkina Faso, has a low rate of $\mathrm{CS}$, have reported women's experiences of cesarean birth. ${ }^{15,17,18}$ In a study of 413 women in Nigeria reported by Aziken et al, high costs (19.8\%) ranked third in the list of reasons for refusing CS, after fear of dying (31.7\%) and fear of pain $(29.1 \%)$. The feeling of failure followed in fourth place (7.2\%). ${ }^{15}$ Many women reported general mental distress after CS. It is noteworthy that, in Nigeria, women who cannot deliver vaginally are believed to have not prayed enough, to have been unfaithful to their husbands, or to be witches. ${ }^{15}$ In another Nigerian study including 6,224 patients, Ezechi et al reported that only $33.3 \%$ of women believed that CS was carried out for a medical indication. ${ }^{17}$ Other reasons given were that hospitals and staff want to make a profit $(42.7 \%)$ or that young doctors want to practice performing the procedure $(29.3 \%)$. In a study of CS in 145 women from Ghana, women who preferred vaginal deliveries said that "vaginal is best", with no long-term pain, less risk of dying, and less cost. ${ }^{16}$ Women who preferred CS described it as a quick and easy delivery method accompanied by fewer labor pains. There were no significant associations between choice of delivery mode and the individual characteristics of the women (ie, age, marital status, education, and place of residence). It is interesting that there was a fear of pain in both groups. Women who underwent a CS wanted to avoid the pain of labor and childbirth, and women who chose to deliver vaginally wanted to avoid post-CS pain. Fear of dying 
during or following a CS is real in many African countries, where we see an increased mortality rate even in women undergoing elective CS without risk factors. ${ }^{18,30}$ Mazzoni et al did a systematic review to explore women's preference for $\mathrm{CS}$, and found an overall pooled preference for CS of $15.6 \%$. In a subgroup meta-analysis by region worldwide, the highest preference for CS was found in the Americas, comprising the USA, Canada, and Latin America (21.3\%, 95\% confidence interval 16.4-26.7), ${ }^{31}$ and within the American subgroups, the preference for CS was higher in Latin America than in the USA or Canada. Unfortunately, the African region was under-represented in this meta-analysis, with only one study from South Africa meeting the inclusion criteria. An exploration of women's preferences for CS in the different regions of Africa would be interesting.

\section{Physical, medical, economic, and social vulnerability}

Cesarean birth increases the vulnerability of women. If we refer to Soulet's definition:

"The vulnerability is understood as endogenous to the characteristics of the social system, interacting with the system properties and those individuals who are members.

But those who cannot $[\ldots]$ actively participate in the continuous production of the collective life, become highly vulnerable." 32

An African woman who undergoes a CS runs a greater risk of dying than her Latin American or Asian counterparts, according to a major World Health Organization study on maternal health. ${ }^{11,30,33}$ Supply problems with essential drugs and poor quality services result in low quality care and can lead to fatal anesthetic accidents. CS carried out in cases of prolonged labor and the resulting infections leave the CS scar vulnerable. The risk of uterine rupture increases in a subsequent pregnancy, and may be fatal if it occurs at home or in a small health center distant from the hospital. In the Severe Maternal Morbidity in West Africa (MOMA) study, $\mathrm{CS}$ increased the risk of uterine rupture during subsequent pregnancies by eleven-fold. In settings of poor access to emergency obstetric care, a third of women who suffered a uterine rupture died (33.3\%), while half lost their child $(52 \%) .{ }^{34}$

Care is expensive and not covered by social security systems. A CS may leave a family in debt, and can endanger a couple's relationship when the husband blames the wife for impoverishment of the family. He may even choose another woman to bear his future children for fear that the present one may need more cesarean births. ${ }^{17,21,35}$ In some communities, a woman may feel rejected by other women if she is not able to deliver vaginally. A study by Ezechi et al reported that $26.8 \%$ of patients in Nigeria who had a CS said that they would rather die than have another. ${ }^{17}$ The reasons given for refusing a second intervention were feelings of failure (81.2\%) and the financial implications $(66.5 \%)$.

This study emphasizes the importance of showing that one is strong enough to deliver vaginally. The aversion towards CS is deeply rooted in culture and tradition, and the level of education in this sample of 6,224 women had very little influence on their opinion regarding the issue. This aversion may endanger women. Ezechi et al described how one woman was rejected by her in-laws after a CS. She was accused of not knowing how to care for the child because she had not experienced the pain of childbirth. During the next pregnancy, she remained brave as long as possible in a small mission clinic but was transferred to the emergency services of the hospital with uterine rupture. She survived, but lost her child and her uterus. ${ }^{17}$

\section{Conclusion}

For women and their families, the experience of cesarean birth involves multiple challenges. Cultural perceptions associate vaginal birth with femininity. A cesarean birth is not valued by women or their families because it is seen as a failure to reach "woman-mother" status. Given that this status exists only through the eyes of others, the sense of failure acquires its full meaning indirectly via discourse with family or community members.

The economic implications are no less significant. The cost of CS can be quite substantial for urban and rural households. Even if exemption schemes exist, the costs remain important for the family and especially for the man, who assumes social responsibility for health care spending. Further, women feel guilty for incurring these additional costs. Finally, both parties are left with questions about the need for such an intervention in the future. A cesarean birth makes a woman vulnerable in her relationship.

Popular perceptions are also related to the quality of care that women receive for their CS. Testimonies of their fears point to a crisis of confidence with regard to the procedure and the impact it can have on women's health. Fear of dying and fear of side effects reveal the level of distrust in health care services.

Poor quality of care and the economic burden of CS place women in a multifaceted situation of vulnerability within their families. CS has a medical, emotional, social, and economic impact for poor African women. Impact of CS cannot be 
underestimated and the intervention cannot be performed without a medical indication in such a context of substandard care. Maternal health program managers need to understand women's perceptions of CS so as to overcome existing barriers to this life-saving procedure. These interviews were conducted before the introduction of the national subsidy in Burkina Faso. We encourage researchers to conduct similar research among users of maternity wards and women who have undergone CS to see if the increased affordability of CS has changed their experiences and perceptions of the procedure.

\section{Acknowledgments}

This work is based on data gathered as part of the "Amélioration de la Qualité et de 1'Accès aux Soins Obstétricaux d'Urgence" (AQUASOU) project funded by the French Ministry of Foreign Affairs (Projet FSP 2001-149). We would like to thank the Bogodogo District management team in Ouagadougou, the maternity and operating theater staff for their commitment to and involvement in the home visits, the women and their families for their trust, and the team at the Health and Family Directory of the Ministry of Health for its constant support.

\section{Disclosure}

The authors report no conflicts of interest in this work.

\section{References}

1. UON Network. L'approche des Besoins Obstétricaux Non Couverts pour les Interventions Obstétricales Majeures: Etude comparative Bénin, Burkina Faso, Haïti, Mali, Maroc, Niger, Pakistan et Tanzanie. Antwerp, Belgium: Institute of Tropical Medicine; 2003.

2. De Brouwere V, Dubourg D, Richard F, Van Lerberghe W. Need for caesarean sections in west Africa. Lancet. 2002;359:974-975.

3. Dumont A, de Bernis L, Bouvier-Colle MH, Bréart G. Caesarean section rate for maternal indication in sub-Saharan Africa: a systematic review. Lancet. 2001;358:1328-1333.

4. Francome C, Savage W. Caesarean section in Britain and the United States $12 \%$ or $24 \%$ : is either the right rate? Soc Sci Med. 1993;37: 1199-1218.

5. King CR. The New York Maternal Mortality Study: a conflict of professionalization. Bull Hist Med. 1991;65:476-502.

6. [No authors listed]. What is the right number of caesarean sections? Lancet. 1997;349:815.

7. O'Driscoll K, Foley M. Correlation of decrease in perinatal mortality and increase in cesarean section rates. Obstet Gynecol. 1983;61:1-5.

8. O'Sullivan JF. Caesarean birth. Ulster Med J. 1990;56:1-10.

9. Porges RF. The response of the New York Obstetrical Society to the report by the New York Academy of Medicine on maternal mortality, 1933-1934. Am J Obstet Gynecol. 1985;152:642-649.

10. Paterson-Brown S. Should doctors perform an elective caesarean section on request? Yes, as long as the woman is fully informed. $B M J$. 1998;317:462-463.

11. Souza JP, Gulmezoglu A, Lumbiganon P, et al. Caesarean section without medical indications is associated with an increased risk of adverse short-term maternal outcomes: the 2004-2008 WHO Global Survey on Maternal and Perinatal Health. BMC Med. 2010;8:71.
12. Amu O, Rajendran S, Bolaji II. Should doctors perform an elective caesarean section on request? Maternal choice alone should not determine method of delivery. BMJ. 1998;317:463-465.

13. Behague DP. Beyond the simple economics of cesarean section birthing: women's resistance to social inequality. Cult Med Psychiatry. 2002;26:473-507.

14. Behague DP, Victora CG, Barros FC. Consumer demand for caesarean sections in Brazil: informed decision making, patient choice, or social inequality? A population based birth cohort study linking ethnographic and epidemiological methods. BMJ. 2002;324:942-945.

15. Aziken M, Omo-Aghoja L, Okonofua F. Perceptions and attitudes of pregnant women towards caesarean section in urban Nigeria. Acta Obstet Gynecol Scand. 2007;86:42-47.

16. Danso K, Schwandt H, Turpin C, Seffah J, Samba A, Hindin M. Preference of Ghanaian women for vaginal or caesarean delivery postpartum. Ghana Med J. 2009;43:29-33.

17. Ezechi OC, Fasubaa OB, Kalu BE, Nwokoro CA, Obiesie LO. Caesarean delivery: why the aversion? Trop J Obstet Gynaecol. 2004;21:164-167.

18. Oladapo OT, Lamina MA, Sule-Odu AO. Maternal morbidity and mortality associated with elective caesarean delivery at a university hospital in Nigeria. Aust NZ J Obstet Gynaecol. 2007;47:110-114.

19. Borghi J, Hanson K, Acquah CA, et al. Costs of near-miss obstetric complications for women and their families in Benin and Ghana. Health Policy Plan. 2003;18:383-390.

20. Borghi J, Storeng KT, Filippi V. Overview of the costs of obstetric care and the economic and social consequences for households. In: Richard F, Witter S, De Brouwere V, editors. Reducing Financial Barriers to Obstetric Care in Low-Incomes Countries. Antwerp, Belgium: ITG Press; 2008.

21. Storeng KT, Baggaley RF, Ganaba R, Ouattara F, Akoum MS, Filippi V. Paying the price: the cost and consequences of emergency obstetric care in Burkina Faso. Soc Sci Med. 2008;66:545-557.

22. Programme d'Amélioration de la Qualité et de l' Accès aux Soins Obstétricaux d'Urgence dans les pays en développement. Composante 2 Burkina Faso. Rapport final d'activités du 1er janvier 2003 au 31 mars 2006. Ministère des Affaires Etrangères Française, editor. Antwerp, Belgium: Institute of Tropical Medicine; 2006.

23. Ouedraogo C, Bazié D, Gruenais ME, et al. Programme d'amélioration de la qualité et de l'accès aux soins obstétricaux d'urgence dans les pays en développement. Analyse situationnelle, Secteur 30, Ouagadougou: Composante 2, Burkina Faso, Institute of Tropical Medicine. Antwerp, Belgium: Institute of Tropicale Medicine; 2003.

24. Copans J. L'Enquête Ethnologique de Terrain. Paris, France: Nathan; 2011.

25. Olivier de Sardan J-P. La Rigueur du Qualitatif: Les Contraintes Empiriques de l'Interprétation Socio-Anthropologique. Louvain-LaNeuve, Belgique: Academia-Bruylant; 2008.

26. Olivier de Sardan J, Moumouni A, Souley A. ["L'accouchement c'est la guerre": accoucher en milieu rural nigérien]. Afr Contemp. 2000;195:136-154.

27. Gruenais ME, Ouattara F. Le "prix de l'accouchement". La prise en charge de la grossesse en Afrique Subsaharienne. In: Familles et Santé: Le Regard des Sciences Sociales. Rennes, France: Presses de 1'Ecole des Hautes Études en Santé Publique; 2010.

28. Ouattara F, Bationo F, Gruenais ME. [Pas de mère sans un «mari». La nécessité du mariage dans les structures de soins à Ouagadougou (Burkina Faso)]. Autrepart. 2009;52:79-92.

29. Ouédraogo R. Les évacuations sanitaires des femmes enceintes à la maternité du CSPS du secteur 28 de Ouagadougou. Thesis. Burkina Faso, West Africa: Université de Ouagadougou; 2006.

30. Shah A, Fawole B, M'imunya JM, et al. Cesarean delivery outcomes from the WHO global survey on maternal and perinatal health in Africa. Int J Gynaecol Obstet. 2009;107:191-197.

31. Mazzoni A, Althabe F, Liu NH, et al. Women's preference for caesarean section: a systematic review and meta-analysis of observational studies. BJOG. 2011;118:391-399. 
32. Soulet M-H. [Reconsidérer la vulnérabilité]. Empan. 2005;4:24-29.

33. Souza JP. Caesarean section without medical indication increases risk of short-term adverse outcomes for mothers. Policy brief WHO/ RHR/HRP/10.20. Geneva, Switzerland: World Health Organization; 2010. Available from: http://whqlibdoc.who.int/hq/2010/WHO_RHR_ HRP_10.20_eng.pdf. Accessed February 25, 2014.
34. Ould El Joud D, Prual A, Vangeenderhuysen C, Bouvier-Colle MH. Epidemiological features of uterine rupture in West Africa (MOMA study). Paediatr Perinat Epidemiol. 2002;16:108-114.

35. Filippi V, Ganaba R, Baggaley RF, et al. Health of women after severe obstetric complications in Burkina Faso: a longitudinal study. Lancet. 2007;370:1329-1337. 


\section{Supplementary material}

\section{Interview guide}

For women with cesarean section, Bogodogo District, Ouagadougou

\section{Identification}

Age

Number of children

Profession

Education

Spouse's occupation

Spouse's level of education

Places of residence

Address/telephone number

\section{Notion of a difficult pregnancy}

How was this pregnancy?

Was it a difficult pregnancy?

Have you ever had a difficult pregnancy?

How were your other pregnancies?

What can make a pregnancy difficult?

Have you ever lost a child in childbirth? If so, when did this happen? Where? Can you tell us a little about how it happened?

\section{Medical supervision of the last pregnancy}

Did you attend antenatal consultations?

If so, how many?

Where? Explain the criteria of choice for the medical facility

Have you attended the discussion sessions ("causeries") given by the midwife during pregnancy?

What did the midwives say during these sessions?

During the antenatal consultation, what did caregivers tell you personally?

About childbirth, what were you told?

What did you learn during antenatal consultation? During the discussion sessions?

\section{Childbirth and the perception of it}

Can you talk about your delivery?

Do you have any idea when the pain started?

Who did you discuss it with?

What did you say?

Where was the first place you went for assistance? Why? What were you told there? What care did you receive, if any?

How did you come to maternity ward?

Who decided to send you?

Who accompanied you to the maternity ward?

Who helped you to give birth?

Were you afraid to give birth at the maternity ward?

\section{Cost and financial players of pregnancy and childbirth}

For the antenatal consultation, how much did you pay?

Who paid?

How much did you pay for delivery? Do you know how much your relatives paid? What did you pay yourself? 
Who paid for the delivery?

Did you save money for the childbirth? For the cesarean section? If so, how?

\section{Knowledge of the health facility}

Did you know about the existence of the maternity ward?

Did you know that there was an operating theater in the district hospital? If so, how did you know this? Who told you? When?

\section{Perceptions of health personnel}

How was your relationship with health workers?

Did you know some of them?

What did you like? Why?

What did you dislike? Why?

For the next delivery, would you choose to give birth in the maternity ward?

\section{Proposed solutions}

How could we improve things in the maternity ward?

What should be improved?

Why should we improve the particular point you mention?

What do you suggest to improve conditions for labor at the hospital?

\section{Publish your work in this journal}

The International Journal of Women's Health is an international, peerreviewed open-access journal publishing original research, reports, editorials, reviews and commentaries on all aspects of women's healthcare including gynecology, obstetrics, and breast cancer. The manuscript management system is completely online and includes a very quick and fair peer-review system, which is all easy to use. Visit http://www.dovepress.com/testimonials.php to read real quotes from published authors. 